A01-25008

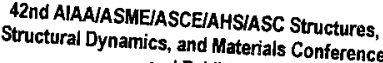

and Exhibit
Seatts Conference

16-19 April 2001

AIAA-2001-1187

\title{
Compressive Response of Circular Cell Polycarbonate Honeycomb Under Inplane Static and Dynamic Loads
}

\author{
Jaeung Chung* and Anthony M. Waas†, \\ Composite Structures Laboratory, \\ Department of Aerospace Engineering, \\ University of Michigan, Ann Arbor, MI, 48109-2140
}

\begin{abstract}
The crushing response of polycarbonate circular cell honeycombs to inplane uniaxial loading is studied through a combination of static and dynamic experiments. The circular cell hexagonally packed honeycomb material has a nearly periodic microstructure. The static experiments correspond to a uniaxial loading condition under displacement control in two different principal inplane directions. The corresponding dynamic experiments are carried out using a low velocity impact drop test facility. Three different initial conditions (corresponding to different drop heights) are used in the dynamic tests. In the initial part of the response, the specimens deform in a almost uniform fashion. Next, a nonlinear phase characterized by progressive localization of deformation is observed. The progressive localization causes the walls of each cell to contact. The reasons for the observed orthotropic response of the honeycombs are discussed. A comparison of the collapse mechanisms between static and dynamic experiments is included.
\end{abstract}

\section{Introduction}

Natural materials such as bone, different types of wood and cork are materials that have a cellular microstructure. In order to use the efficiency of these microstructures, man-made materials mimicking such microstructures have emerged. Examples are polymeric and metallic honeycomb cores used for sandwich structures, crushable metal and polymeric honeycomb for energy-absorbing applications. In industry, man-made cellular materials are increasingly used to make light and stiff structures or structures

\footnotetext{
*Research Fellow.

†Professor of Aerospace Engineering, Associate Fellow AIAA.

${ }^{0}$ Copyright (c) 2001 by Anthony M. Waas. Published by the American Institute of Aeronautics and Astronautics, Inc. by permission.
}

that need to absorb energy during their service lifetime.

The mechanical properties of cellular materials were initially studied by Gent and Thomas [1]. Gibson and co-workers [2] calculated the inplane Young's moduli and Poisson's ratios of hexagonal cell honeycombs for loading in two orthogonal directions. They identified buckling and plastic collapse mechanisms and derived equations for the collapse stresses. Investigations into the effects of elastic properties of non-periodic honeycombs were reported by Silva, Hayes and Gibson [3]. Gibson and Ashby [4] presented expressions for the mechanical properties such as the moduli and collapse strengths of three dimensional cellular solids. In another work [5], they analyzed uniaxial loading and in a limited manner biaxial loading using the approximation of a constant rotational stiffness of the node where three cell walls meet. Papka and Kyriakides [6] studied the load-displacement response under displacement control using hexagonal aluminum honeycomb specimens. These researchers also investigated the mechanical response of circular celled honeycomb under uniaxial loading in one direction and also the response to biaxial loading using a specially designed biaxial loading fixture [7,8]. Lagace and Vizzini [9] investigated the properties of an aluminum honeycomb core in conjunction with their study to develop a sandwich column specimen for characterizing the uniaxial compressive strength of composite laminates. These authors studied several different materials and cell sizes in their experimental program. Recently, Chung and Waas [10] have reported the static biaxial response of polycarbonate honeycombs.

An important goal of the present study is to develop a robust and well tested continuum description of the honeycomb as a 3D solid. The present study of inplane collapse mechanisms of the honeycomb material is complementary to the task of devel- 
oping a 3D continuum model of the honeycomb material. To achieve this goal, collapse mechanisms of polycarbonate circular cell honeycomb under different uniaxial loading conditions were studied through static and dynamic loading. In the static case, two types of experiments were conducted on the honeycomb specimens. The first experiment was aimed at examining the static collapse mechanism of the honeycomb material under uniaxial, compressive loading in the X-direction (see Figure 1 for nomenclature). The other was aimed at studying the static collapse mechanism of the honeycomb material under uniaxial compressive loading in the Y-direction (Figure 1). In the dynamic case, a total of six types of experiments were performed. The first three compressive experiments investigate the dynamic response of the honeycomb material under three different uniaxial impact loads in the $\mathrm{X}$-direction, while the other three compressive experiments were executed in order to study the dynamic response of the honeycomb material under three different uniaxial impact loads in the Y-direction. The Young's modulus of the polycarbonate material used in the test is $2.4 \mathrm{GPa}$, and the Poisson's ratio is 0.3. The stressstrain curve of the polycarbonate material that is used to manufacture the honeycomb is shown in Figure 2 taken from [11]. In theory, a hexagonally packed circular cell honeycomb must be transversely isotropic (the X-Y plane being the plane of isotropy), but in practice, due to various imperfections, as noted later, these materials are best classified as being orthotropic. A detailed characterization of the elastic mechanical properties of the honeycomb is given in Chung and Waas [12].

\section{Test Specimen Geometry}

The dimensions of the test specimens are described in Figure 1(b). The test specimens consist of "twelve by twelve" cells cut from a $30.5 \mathrm{~cm}$ by $30.5 \mathrm{~cm}$ sheet of honeycomb. Using an optical microscope, various quantities pertaining to the cells in the honeycomb specimens such as cell wall thickness and "radius" of cell were measured accurately. The shape of each cell in the test specimen is not perfectly circular, but deviates slightly from circularity. The distribution of aspect ratio (the ratio between the diameter in the $\mathrm{X}$-direction and the diameter in the Y-direction for each cell of the specimen) is shown in Figure 3. Also, Figure 3 shows the mean values of "a" (the diameter in the X-direction), " $\mathrm{b}$ " (the diameter in the Y-direction) and " $\mathrm{t}$ " (single wall thickness) obtained using an optical microscope. As shown in Figure 4, the wall thickness of a single cell varies along the cell circumference. The values of a single wall thickness and double wall thickness (corresponding to the region of contact between neighboring cells) are as shown in Figure 4.

\section{Static Case}

\subsection{Experimental Procedure}

Static compressive experiments were conducted under displacement control in a hydraulic four actuator serve controlled test frame. The overall experimental setup used is shown schematically in Figure 5. Honeycomb specimens were placed between an upper and a lower solid steel plate. These plates are hardened, ground and have lubricated surfaces. The upper and the lower loading plates are mounted on the upper and lower actuators of the test frame respectively. The upper actuator and the lower actuator of the test frame move at the same time collinearly in opposite directions. To record the specimen axial shortening measured through an LVDT (Linear Voltage Displacement Transducer) and the specimen load measured through a load cell installed on the upper loading plate, an inhouse data acquisition system was used. The measured loads were normalized by the undeformed effective crosssectional area and the specimen axial shortening is normalized by the undeformed height of the specimens. These measures of effective macroscopic stress $\left(\Sigma_{i}\right)$ and normalized axial end shortening $\varepsilon_{i}$ (also referred to as macroscopic strain) are used for presentation of the experimental results. The subscript ' $i$ ' is used to denote the direction of applied load. All tests are conducted in a quasi-static fashion with a cross-head speed of $0.025 \mathrm{~mm} / \mathrm{sec}$.

\subsection{Static Compressive Loading in the $\mathrm{X}$-direction}

The experimental response of a honeycomb specimen under a static compressive loading in the $\mathrm{X}$ direction is shown in Figure 6(a). Figure 6(b) shows a sequence of deformed configurations of the specimen in the experiment. In Figure 6(a), the straight line is the $\Sigma_{x}-\varepsilon_{x}$ response as measured in the experiment. In the first phase of the experimental response, the specimen deforms in a uniform fashion (see figure 6(b)-exs1). The 'slope' of the response begins to undergo a slight change around a stress of $20 \mathrm{KPa}$ (see figure $6(\mathrm{~b})$-exs1). This implies that the response becomes nonlinear due to a reduction in the stiffness of the specimen. In this nonlinear 
regime, the specimen is 'stable' because the load increment required for further deformation of the specimen is positive. The continuous reduction of the stiffness of the specimen results in a gradually weakening response until the attainment of a maximum load. During this region of the response which is still nonlinear and stable, a cluster of cells shows a tendency to collapse resulting in deformation localization. The initiation of localization is clearly seen in Figure 6(b)-exs4. In this figure, the localization is seen to initiate along diagonal lines of the specimen, that is, from a cell at the bottom row (right end of picture, marked A) and at an angle of 117 degrees from the positive $\mathrm{X}$-axis. The significant development of the localization results in a negative stiffness of the specimen.

\subsection{Static Compressive Loading in the Y-direction}

The experimental response of a honeycomb specimen under a static compressive loading in the $\mathrm{Y}$ direction is shown in Figure 7(a). Figure 7(b) shows a sequence of deformed configurations of the specimen in the experiment. In Figure 7(a), the straight line is the load-displacement response in the experiment. In the first part of the experimental response, the specimen deforms symmetrically about the axis of loading (see Figure 7(b)-eys1). The slope of the response begins to change slightly at $27 \mathrm{KPa}$ (see Figure 7(b)-eys2). This implies that the response becomes nonlinear due to a reduction in the stiffness of the specimen. In this nonlinear phase, the specimen is stable and initiation of deformation localization is observed at the center cells in the first, second, third and fourth rows from the bottom row. A continuous reduction in the stiffness of the specimen progressively occurs until the maximum load is reached. In this decreasing stiffness region, the response is still stable. The development of the localization is clearly seen in Fig. 7(b)-eys3. In Figure 7 (b)-eys 3 , the localization is completely developed in four rows (from the bottom row), and some center cells in the adjacent fifth row. In Figure 7(b)-eys4, the localization is completely developed up to and including the fifth row. As seen in Fig. 7(b)-eys2, Fig. 7(b)-eys3 and Fig. 7(b)-eys4, the regions of collapsing cells gradually spread from row to row. The fully developed localization causes a faster reduction in the stiffness of the specimen beyond the maximum load. In Fig. 7(b)-eys6, the completely collapsed third row deforms significantly more when compared to other rows in which cells are also collapsed. This shows that the deformation is localized in this row. In Fig. 7(b)-eys7, the walls of each cell in the third row contact each other and the corresponding slope of the response is negative. The slope of the response corresponding to Fig. 7(b)eys 8 is positive, while that corresponding to Fig. 7 (b)-eys 9 is negative. The series of photos shown in Fig. 7(b)-eys7, Fig. 7(b)-eys 8 and Fig. 7(b)eys 9 , reveal progressively increasing amounts of cell wall contact. When this process occurs, the corresponding stress-normalized end shortening response curve displays an up-down-up oscillatory feature. In other words, whenever each cell completely collapses thereby resulting in a zero local stiffness contribution momentarilly, the slope of the response turns negative and immediately becomes positive as cell wall contact begins, once again. This mechanism occurs only beyond the maximum load.

\section{Dynamic Case}

\subsection{Experimental Procedure}

Dynamic compressive experiments were performed using the polycarbonate circular cell honeycomb specimens in a drop tower. The experimental setup used is shown schematically in Figure 8. Honeycomb specimens are placed between an upper solid steel plate and a lower solid steel block which have hardened, ground and lubricated surfaces. An upper solid steel block is connected between two ball bushing bearings installed into two circular steel rods. In order to prevent the test specimen from moving from their original location when the upper loading plate impacts the specimen, the specimen is attached to the lower steel block using an epoxy adhesive. Surfaces of the circular bars are smooth and lubricated in order to prevent friction when the solid block is dropped in the $\mathrm{Y}$ direction (Figure 8). A load cell is mounted between the upper loading plate and the upper block. An accelerometer is installed on the upper block. To record impact load data through the load cell and acceleration data of the specimen through the accelerometer, a four channel high rate oscilloscope is used. The oscilloscope can acquire digitized data at high sampling rates (maximum sampling rate of the oscilloscope is $2 \mathrm{GHz}$ ). In these dynamic experiments, a sampling rate of 10 $\mathrm{KHz}$ is used for the oscilloscope. The axial displacement of the specimen (in the direction of the falling impactor) is obtained after double integration of the acceleration data. In addition, a high speed digital camera is used to record the deformation shapes of the honeycomb specimen. The camera has a maximum framing rate of 1000 frames/sec, for a total 
duration of 2.8 secs. In the present experiments, this maximum framing rate is used. The measured loads (through the load cell) are normalized by the undeformed effective cross-sectional area and the displacements of the specimen are normalized by the undeformed height of the specimen. These measures of effective stress and effective strain similar to what was used for the static case are used for presentation of dynamic experimental results. The upper loading plate connected to the upper block is dropped on the honeycomb specimen at three different heights in two different inplane directions (the $\mathrm{X}$ and $\mathrm{Y}$ direction (Figure $1(\mathrm{a})$ )). These directions are the material principal orthotropic directions. In each direction, the test specimen is collapsed by the upper loading plate free falling from three different heights. This results in three different initial impact velocities. Hence, a total of 6 tests are performed in the dynamic experiment. Three different heights ( $h_{1}, h_{2}, h_{3}$; the initial distance between the upper loading plate and top of the test specimen) and velocities in each direction are shown in Figure 9. The initial impact velocity of the upper loading plate $\left(v_{1}, v_{2}, v_{3}\right.$; see Figure 9$)$ is obtained using the following simple equation.

$$
m g h=\frac{1}{2} m v^{2} \rightarrow v=\sqrt{2 g h} .
$$

For the heights used in the present experiment, this equation was found to be accurate upto $97 \%$ of the value measured, when calibrated against measurements made through the images of the high speed camera.

\subsection{Dynamic Compressive Loading in the X-direction under an Ini- tial Impact Velocity of $\mathbf{5 8 5 . 1 6}$ $\mathrm{mm} / \mathrm{sec}$}

The experimental response of a honeycomb specimen under an impact compressive loading, corresponding to an initial impact velocity of 585.16 $\mathrm{mm} / \mathrm{sec}$ in the $\mathrm{X}$ direction is shown in Figure 10(a). Figure 10(b) shows a sequence of deformed configurations of the specimen in the experiment. In Figure $10(\mathrm{a})$, the straight line is the stress-strain response in the experiment and square symbols in the response curve indicate the corresponding deformed shapes shown in Figure 10(b). In Figure 10(a), the response of the honeycomb specimen is shown upto the maximum displacement of the specimen during the impact event. At the end of this response, the specimen starts to recover, with a reversal in the ax- ial displacement. That is, stress and strain of the response start to reduce.

In the first phase of the experimental response, the specimen deforms in a uniform fashion (See Figure 10(b)-exd1). The slope of the response begins to change around $\Sigma_{x}=24 \mathrm{KPa}^{1}$. This implies that the impact response becomes nonlinear due to a reduction in the stiffness of the specimen. In this nonlinear regime, further deformation of the specimen requires an increase in the external load. This implies that the specimen is stable until the attainment of a maximum load. Figure 10(b)-exd3 (stable nonlinear regime) shows the initiation of deformation localization scattered throughout the specimen. In Figure 10(b)-exd4, the localization is clearly seen and propagation of the localization results in the formation of diagonal deformation bands in the specimen similar to the results of the static experiment. This localized band is clearly seen in Figure 10(b)exd5. In Figure 10(b)-exd5, the severest development of this band is seen along the diagonal from the fifth cell (from the left end of the top row) to the second cell (from the right end of the bottom row). This diagonal localized band in the specimen results in a negative macroscopic stiffness of the specimen. That is, the localized band causes a reduction in load for subsequent increase of axial deformation.

\subsection{Dynamic Compressive Loading in the Y-direction under an Ini- tial Impact Velocity of $\mathbf{7 0 1 . 9 6}$ $\mathrm{mm} / \mathrm{sec}$}

The experimental response of a honeycomb specimen corresponding to an initial impact velocity of $701.96 \mathrm{~mm} / \mathrm{sec}$ in the $\mathrm{Y}$ direction is shown in Figure 11(a). Figure 11(b) shows a sequence of deformed configurations of the specimen in the experiment. In Figure 11(a), the straight line is the stress-strain response in the experiment and the square symbols indicate the stress and strain values corresponding to the deformed shapes shown in Figure 11(b). Figure 11(a) shows the specimen response upto and including the maximum axial deformation. Beyond this, the specimen experiences a reduction in the macroscopic strain (and the correponding macroscopic stress). In the first part of the experimental response, the specimen experiences symmetric uniform deformation about the $\mathrm{Y}$ direction (see Figure 11(b)-eyd1). In Figure 11(b)-eyd2, initiation of localization is observed in the specimen. The localization causes the slope of the stress-strain response to

\footnotetext{
${ }^{1}$ Positive values of stress correspond to compression.
} 
be changed. That is, the stiffness of the specimen is reduced due to the localization. Figure 11(b)eyd3 shows the localization clearly. The localization is more developed in the cells located on the "left" of the specimen (second and third rows (from the bottom row)) and in some cells located on the right side (sixth and seventh rows (from the bottom row)). Figure 11(b)-eyd4 shows a fully developed localization in the specimen. In Figrue 11(b)-eyd5 and 2.11(b)-eyd6, cell wall contact between adjacent cells in some of the cells is seen to commence. This contact is seen to occur at large values of $\varepsilon_{y} \simeq 0.2$, well into the post localization regime. The corresponding slope of the macroscopic response become positive at this stage. This implies that whenever the cell walls in some areas of the specimen contact each other, the slope of the response curve becomes momentarily positive. Beyond this, the slope of the macroscopic stress-strain response continuously decreases until the next set of cell walls in other areas of the specimen contact each other, when an increase in the instantaneous stiffness occurs.

\section{Discussion}

The response under compressive loading in the $\mathrm{X}$-direction is somewhat more complex when compared to the response under compressive loading in the Y-direction. The linear stiffness of the response is affected by several factors such as cell size, wall thickness and wall thickness variation for each cell and deviation from circularity for each cell of the specimen. The difference between the stiffnesses of the linear regions of the responses under $\mathrm{X}$-direction loading and $\mathrm{Y}$-direction loading is mainly caused by the above mentioned unintended imperfections that are present in the specimens. As shown in Chung and Waas [12], a perfectly circular cell hexagonally packed honeycomb displays macroscopic isotropy. It is therefore prudent to investigate the sensitivity of the specimen stiffness to these different imperfections, the most important being the deviation from circularity of each cell of the specimen. In other words, if each cell of the specimen is perfectly circular, the difference between the stiffnesses of the linear regions of both responses will only be slightly different resulting from the non-uniformity in the thickness distributions along the cell wall contact region (line contact as contrasted against point contact). Even this would disappear as the specimen is scaled up to include a larger number of cells. However, if the aspect ratio $(a / b)$ of each cell of the specimen is larger than 1 , the stiffness of the linear region of the response under uniaxial X-direction loading becomes larger than the corresponding stiffness in the Y-direction. The Young's moduli of the honeycomb material under static and dynamic loading in each inplane direction is shown in Table 1. As seen in Table 1 , the static Young's modulus in the $\mathrm{X}$ direction is similar to the dynamic Young's moduli in the $\mathrm{X}$ direction and the static Young's modulus in the $Y$ direction is lower than the dynamic Young's moduli in the $\mathrm{Y}$ direction. The differences among the dynamic Young's moduli of the specimen in the two inplane principal material directions are not too big. This implies that the inplane linear stiffness of the honeycomb material is independent of the intial impact velocities. Thus, in the regime of strain rates examined in the present work, the macroscopic dynamic response of the honeycomb specimen is rate independent.

Table 3 shows a comparison of the maximum stress vs. the corresponding strain and the maximum strain vs. the corresponding stress in the dynamic experimental response of the honeycomb material in the $\mathrm{X}$ direction. Table 4 is the corresponding comparison in the $\mathrm{Y}$ direction. From Table 3 and Table 4, the maximum stress and maximum strain on the honeycomb material in both inplane directions don't occur at the same time. Furthermore, the maximum stress achieved increases as the impact velocity increases. The experimental results show that the macroscopic response of the honeycomb occurs in two stages. The first stage is a linear response. This is followed by stage of nearly constant load, during which the load oscillates in a "saw-tooth" manner about this constant value. The magnitude of this mean load is dependent on the rate of loading, but the linear stiffness appears to be rate independent. These findings are schematically summarized in Figure 13.

\section{Concluding Remarks}

Results from static and dynamic experiments on the inplane compressive crushing behavior of polycarbonate circular cell honeycombs have been presented. The experimental results show the macroscopic behavior of the honeycombs to be orthotropic. Indeed, there is a considerable difference in the $\mathrm{X}$ and $\mathrm{Y}$ direction response in both the static and $\mathrm{dy}-$ namic cases. Furthermore, there is no considerable difference in the $\mathrm{X}$ direction experimental response between the static and dynamic cases, but a noticeable difference between the static and dynamic cases exists in the $\mathrm{Y}$ direction experimental response (see 
Figure 12). For the range of impact velocities examined, there is no discernible difference in response among the dynamic cases in so far as macroscopic stiffness is concerned. The response corresponding to the $\mathrm{X}$ direction loading is "stiffer" than the corresponding response for the $\mathrm{Y}$ direction loading for both of the static and dynamic cases. In either case, the macroscopic response exhibits two stages. The first stage is a linear response. This is followed by a stage during which the stress exhibits an approximately 'saw tooth' behavior with a mean plateau stress. A companion paper (Chung and Waas [13]) adopts the finite element method to simulate the static and dynamic experimental results.

\section{$\underline{\text { References }}$}

[1] A. N. Gent and A. G. Thomas, "Mechanics of foamed elastic materials", Rubb. Chem. Technol., Vol. 36, pp. 597, 1963.

[2] L. J. Gibson, M. F. Ashby, G. S. Schajer and C. I. Robertson, "The mechanics of two dimensional cellular materials", Proc. R. Soc., A 382, pp. 25,1982 .

[3] M. J. Silva, W. C. Hayes and L. J. Gibson "The effect of non-periodic microstructure on the elastic properties of two-dimensional cellular solids", Int. J. Mech. Sci., Vol. 37, pp 1161, 1995.

[4] L. J. Gibson and M. F. Ashby, "The mechanics of three-dimensional cellular materials", Proc. R. Soc.,A 382, pp. 43, 1982.

[5] L. J. Gibson and M. F. Ashby, "Cellular Solids: Structure and Properties", Pergamon Press, Oxford, 1988.

[6] S. D. Papka and S. Kyriakides, "In-plane compressive response and crushing of honeycomb", J. Mech. Phys. Solids, Vol. 42, pp. 1499, 1994.

[7] S. D. Papka and S. Kyriakides, "In-plane crushing of a polycarbonate honeycomb", Int. $J$. Solids Structures, Vol. 35, pp. 239, 1998.

[8] S. D. Papka and S. Kyriakides, "In-plane crushing of a polycarbonate honeycomb", ASME International Congress Presentation, 1997.

[9] Paul A. Lagace and Anthony J. Vizzini, "The sandwich column as a compressive characterization specimen for thin laminates", ASTM STP 972,Vol. 46, pp. 143, 1988.
[10] J. Chung and A. M. Waas, "Compressive response of circular cell polycarbonate honeycombs under inplane biaxial stresses", J. Engrg. Mech., ASCE, Vol. 127, pp 180, 2001.

[11] S. Kyriakides, private communication, 1996.

[12] J. Chung and A. M. Waas, "The inplane elastic properties of circular cell and elliptic cell honeycombs", Acta Mechanica, Vol. 144, pp 29, 2000.

[13] J. Chung and A. M. Waas, "Compressive response of circular cell polycarbonate honeycombs under inplane uniaxial static and dynamic stresses - simulations", Int. J. Impact Eng., in preparation, 2001.

\begin{tabular}{|l|l|l|l|l|}
\hline \hline $\begin{array}{l}\text { loading con- } \\
\text { dition }\end{array}$ & $\begin{array}{l}E_{x}^{*} \\
(\mathrm{KPa})\end{array}$ & $\begin{array}{l}E_{y}^{*} \\
(\mathrm{KPa})\end{array}$ \\
\hline \hline static & 1176 & 693 & \\
\hline & $v_{1}$ & 1128 & $v_{1}$ & 875 \\
& $(585.16$ & & $(701.96$ & \\
& $\mathrm{mm} / \mathrm{s})$ & & $\mathrm{mm} / \mathrm{s})$ & \\
\cline { 2 - 5 } dynamic & $v_{2}$ & 1120 & $v_{2}$ & 987 \\
& $(831.20$ & & $(917.19$ & \\
& $\mathrm{mm} / \mathrm{s})$ & & $\mathrm{mm} / \mathrm{s})$ & \\
\cline { 2 - 5 } & $v_{3}$ & 1144 & $v_{3}$ & 844 \\
& $(1048.79$ & & $(1118.16$ & \\
& $\mathrm{mm} / \mathrm{s})$ & & $\mathrm{mm} / \mathrm{s})$ & \\
\hline \hline
\end{tabular}

Table 1: Comparison of static and dynamic Young's moduli of the honeycomb material in each inplane direction.

\begin{tabular}{|c|c|c|}
\hline & $\mathrm{X}$ direction & $Y$ direction \\
\hline & $\begin{array}{l}\max . \quad \text { stress } \\
(\mathrm{KPa}) / \text { strain }\end{array}$ & $\begin{array}{l}\max . \quad \text { stress } \\
(\mathrm{KPa}) / \text { strain }\end{array}$ \\
\hline $\begin{array}{l}\text { static load- } \\
\text { ing }\end{array}$ & $52 / 0.1029$ & $37 / 0.1004$ \\
\hline
\end{tabular}

Table 2: A comparison of the maximum stress vs. the corresponding strain in the static experimental response of the honeycomb material. 


\begin{tabular}{|l|l|l|}
\hline \hline \multirow{2}{*}{$\begin{array}{l}\text { initial im- } \\
\text { pact } \\
\text { velocity }\end{array}$} & \multicolumn{2}{|c|}{$\mathrm{X}$ direction impact loading } \\
\cline { 2 - 3 } & $\begin{array}{l}\text { max. stress } \\
(\mathrm{KPa}) / \text { strain }\end{array}$ & $\begin{array}{l}\text { max. strain } \\
\text { stress (KPa) }\end{array}$ \\
\hline \hline $\begin{array}{l}v_{1} \quad(585.16 \\
\mathrm{mm} / \mathrm{s})\end{array}$ & $51 / 0.1067$ & $0.1867 / 48$ \\
\hline $\begin{array}{l}v_{2}(831.20 \\
\mathrm{mm} / \mathrm{s})\end{array}$ & $52 / 0.1066$ & $0.3086 / 51$ \\
\hline $\begin{array}{l}v_{3}(1048.79 \\
\mathrm{mm} / \mathrm{s})\end{array}$ & $55 / 0.1567$ & $0.4395 / 51$ \\
\hline \hline
\end{tabular}

Table 3: A comparison of the maximum stress vs. the corresponding strain and the maximum strain vs. the corresponding stress in the dynamic experimental response of the honeycomb material in the $\mathrm{X}$ direction.

\begin{tabular}{|l|l|l|}
\hline \hline \multirow{2}{*}{$\begin{array}{l}\text { initial im- } \\
\text { pact } \\
\text { velocity }\end{array}$} & \multicolumn{2}{|c|}{ Y direction impact loading } \\
\cline { 2 - 3 } & $\begin{array}{l}\text { max. stress } \\
(\mathrm{KPa}) / \text { strain }\end{array}$ & $\begin{array}{l}\text { max. strain } \\
\text { stress (KPa) }\end{array}$ \\
\hline \hline $\begin{array}{l}v_{1} \quad(701.96 \\
\mathrm{mm} / \mathrm{s})\end{array}$ & $47 / 0.0723$ & $0.2689 / 39$ \\
\hline $\begin{array}{l}v_{2}(917.19 \\
\mathrm{mm} / \mathrm{s})\end{array}$ & $47 / 0.0665$ & $0.4174 / 40$ \\
\hline $\begin{array}{l}v_{3}(1118.16 \\
\mathrm{mm} / \mathrm{s})\end{array}$ & $48 / 0.0708$ & $0.6439 / 42$ \\
\hline
\end{tabular}

Table 4: A comparison of the maximum stress vs. the corresponding strain and the maximum strain vs. the corresponding stress in the dynamic experimental response of the honeycomb material in the $\mathrm{Y}$ direction.

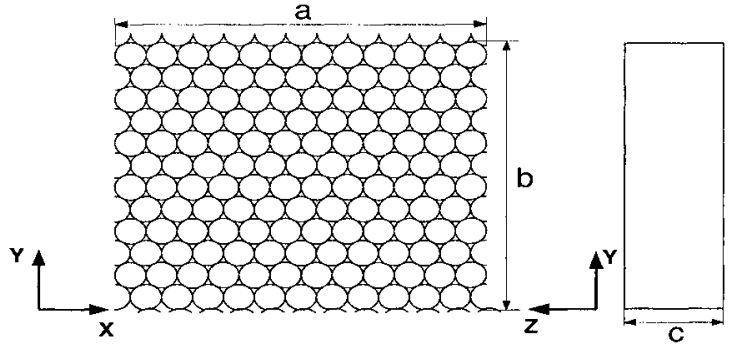

(a)

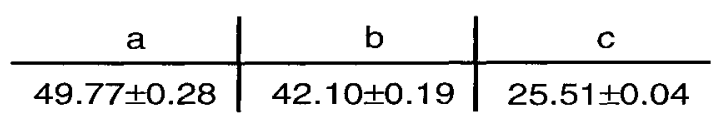

(b)

Figure 1: (a) Geometry of honeycomb specimen used in experiment. (b) Typical dimensions of the test specimens $(\mathrm{mm})$.

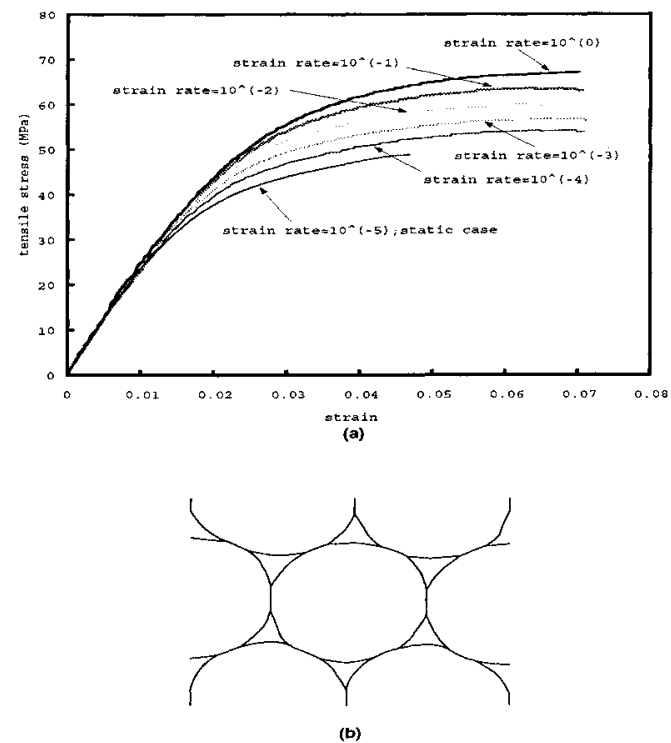

Figure 2: (a) The uniaxial tensile stress-strain curve for polycarbonate material. (b) A microsection of the honeycomb. 
AIAA-2001-1187
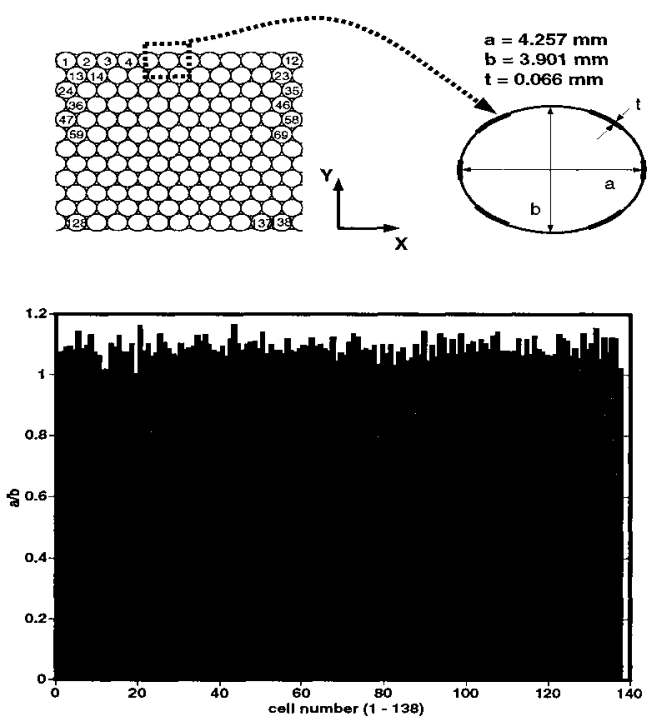

Figure 3: Cell aspect ratio distribution.

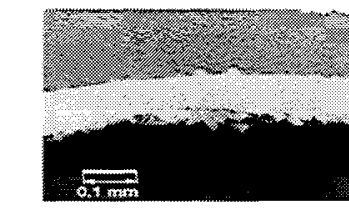

Single Wall Min. Thicknoss $=0.034 \mathrm{~mm}$ Max. Thickness $-0.001 \mathrm{~mm}$

(a)

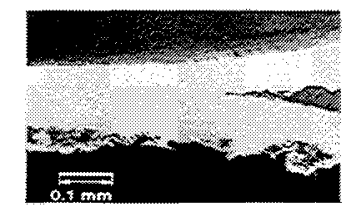

Double Wall TMin. Thickness $=0.119 \mathrm{~mm}$

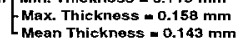

(b)

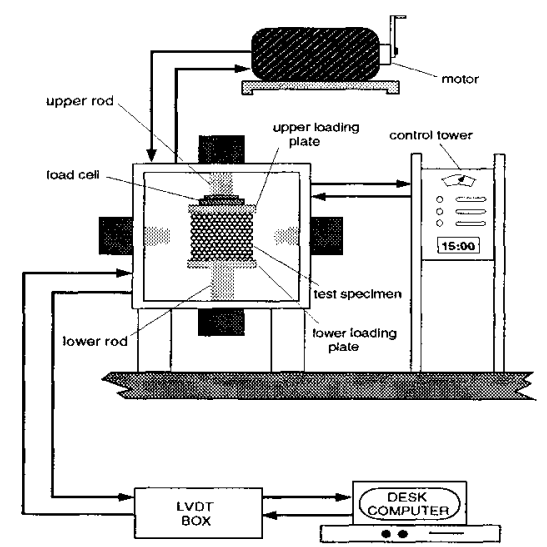

Figure 5: Schematic of test equipment used for static in-plane crushing experiment of honeycomb.

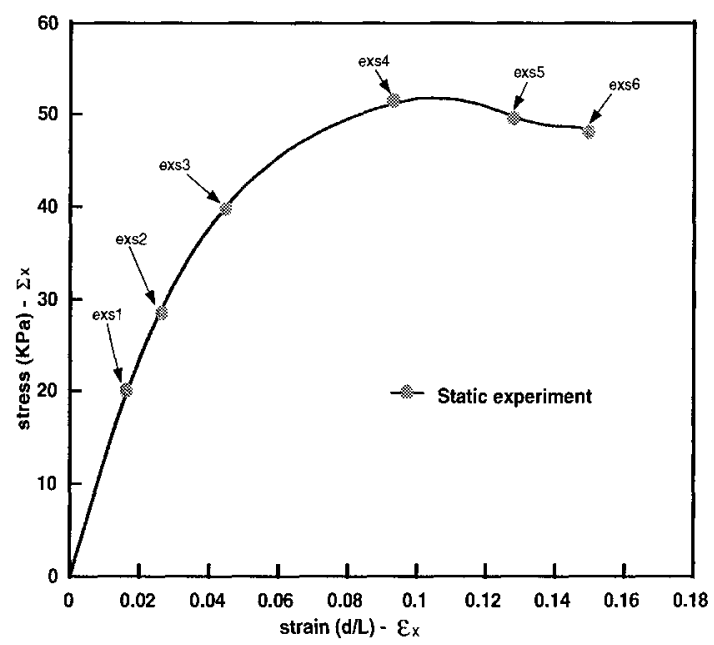

Figure 4: (a) Typical single cell wall thickness variation along each cell of honeycomb. (b) Typical double cell wall thickness variation at the junction of two neighboring cells.

Figure 6: (a) Stress-strain response under static compressive loading in the $\mathrm{X}$-direction. 
AIAA-2001-1187
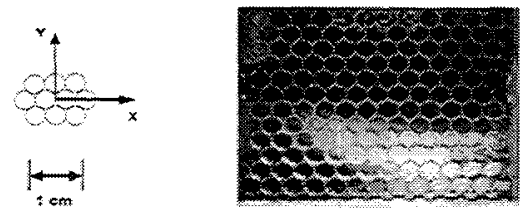

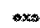

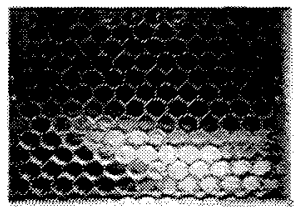

exs2

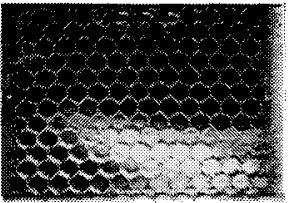

exs3

Figure 6: (b) Experiment - Sequence of deformed honeycomb specimens under static compressive loading in the $\mathrm{X}$-direction.
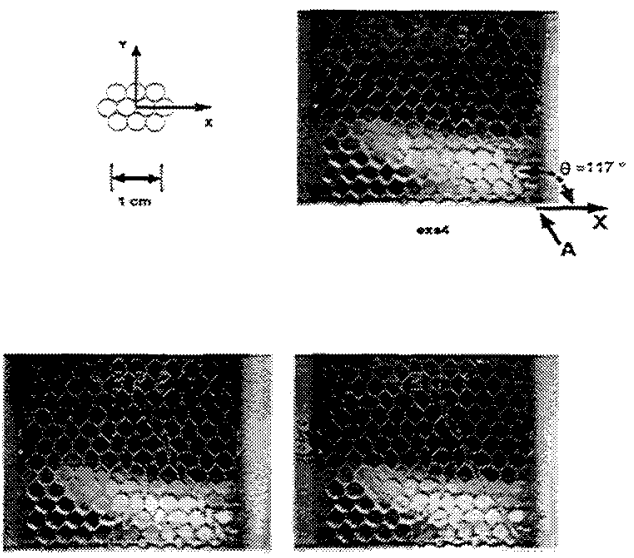

exs5

exs6

Figure 6: (b)-continued; Experiment - Sequence of deformed honeycomb specimens under static compressive loading in the $\mathrm{X}$-direction.

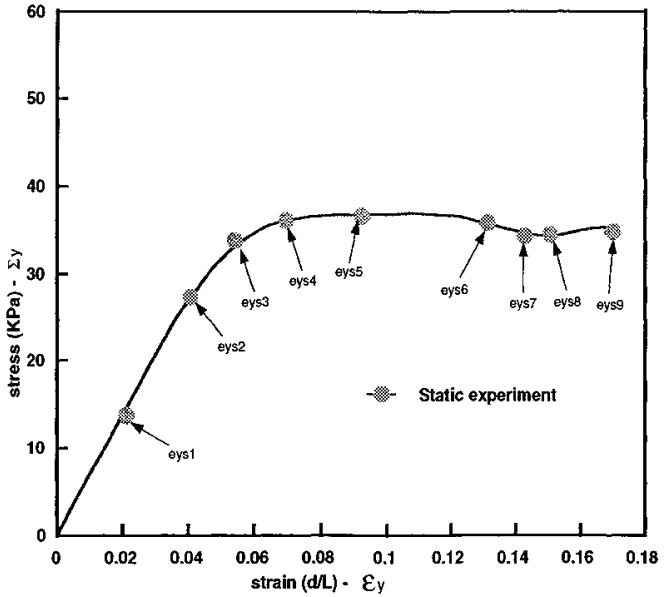

Figure 7: (a) Stress-strain response under static compressive loading in the Y-direction.
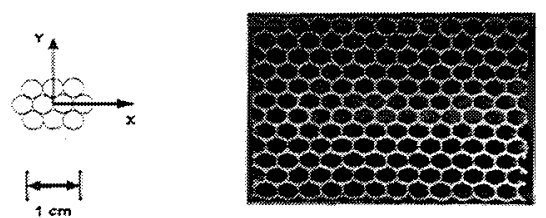

ay:

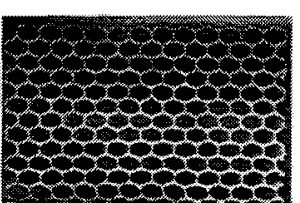

oys2

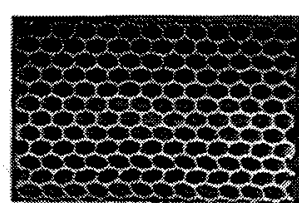

eys3
Figure 7: (b) Experiment - Sequence of deformed honeycomb specimens under static compressive loading in the Y-direction. 


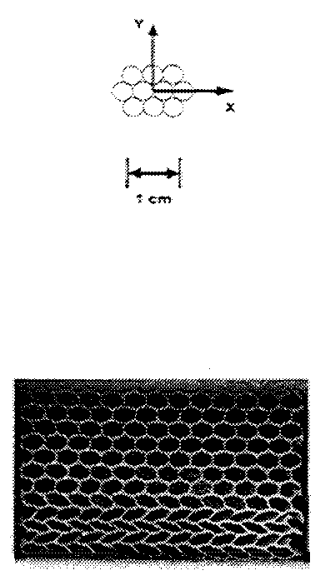

oys5

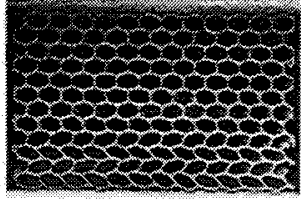

$\rightarrow \mathrm{x}=$

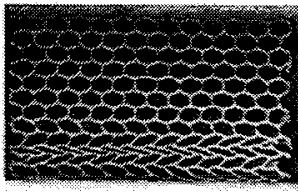

eyse
Figure 7: (b)-continued; Experiment - Sequence of deformed honeycomb specimens under static compressive loading in the $\mathrm{Y}$-direction.

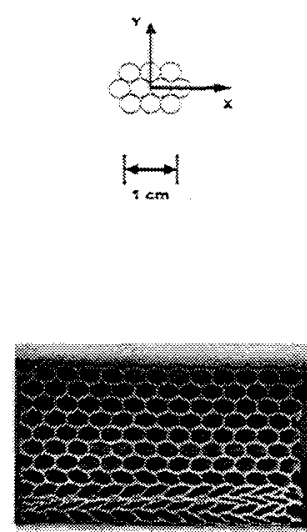

eysa

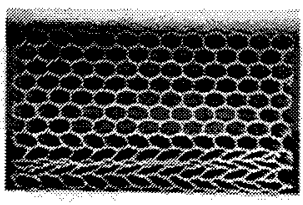

ar:t?

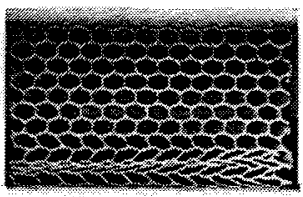

eys9
Figure 7: (b)-continued; Experiment - Sequence of deformed honeycomb specimens under static compressive loading in the $\mathrm{Y}$-direction.
Figure 8: Schematic of test equipment used for dynamic in-plane uniaxial crushing experiment of honeycomb.

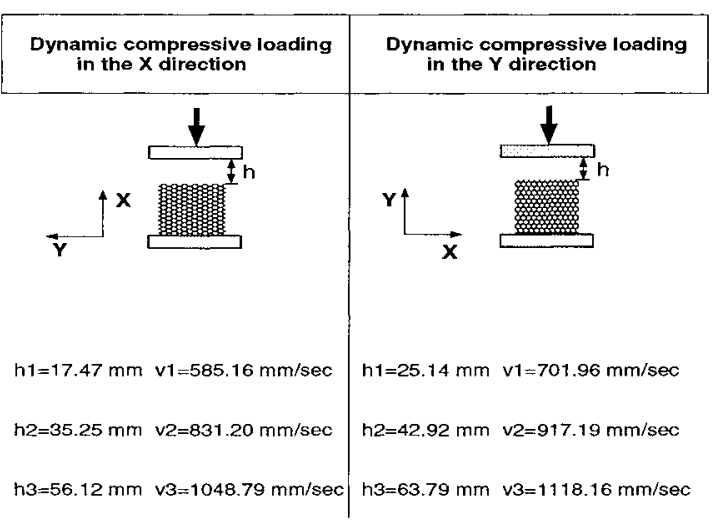

Figure 9: Three different heights and initial impact velocities of dropped upper loading plate. 
AIAA-2001-1187

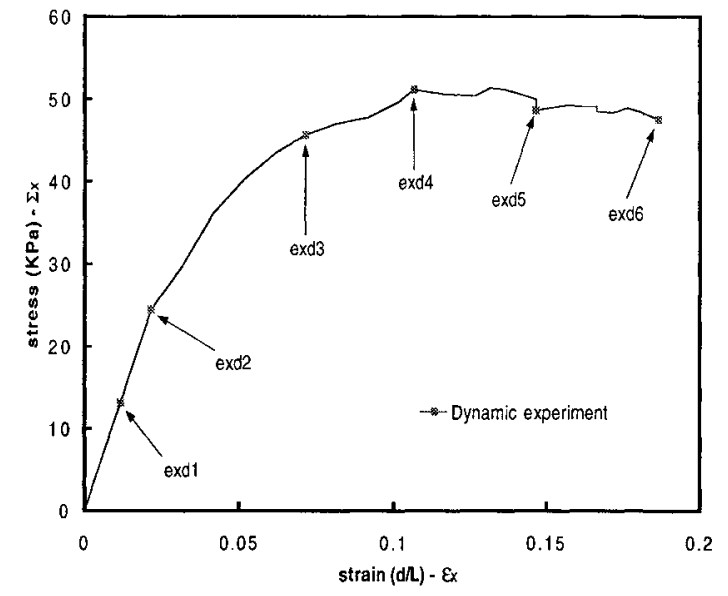

Figure 10: (a) Stress-strain response under dynamic compressive loading in the $\mathrm{X}$-direction.
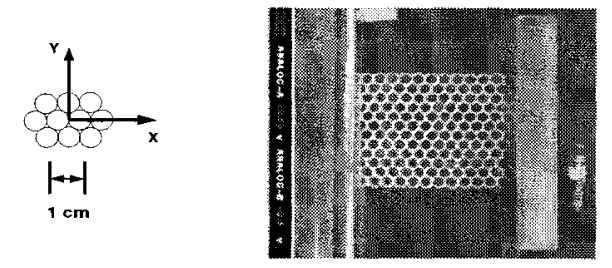

exd1

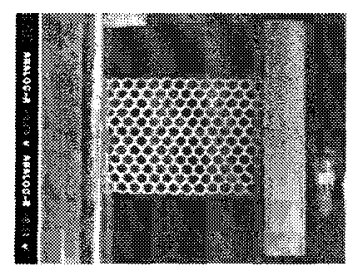

exd2

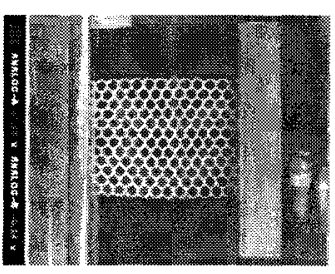

exd3

Figure 10: (b) Experiment - Sequence of deformed honeycomb specimens under dynamic compressive loading in the $\mathrm{X}$-direction.
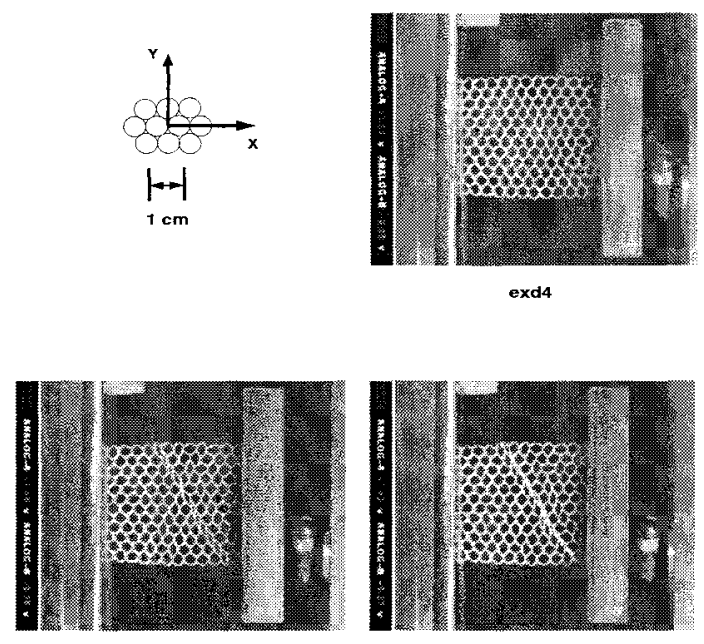

exd5

exd6

Figure 10: (b)-continued; Experiment - Sequence of deformed honeycomb specimens under dynamic compressive loading in the $\mathrm{X}$-direction.

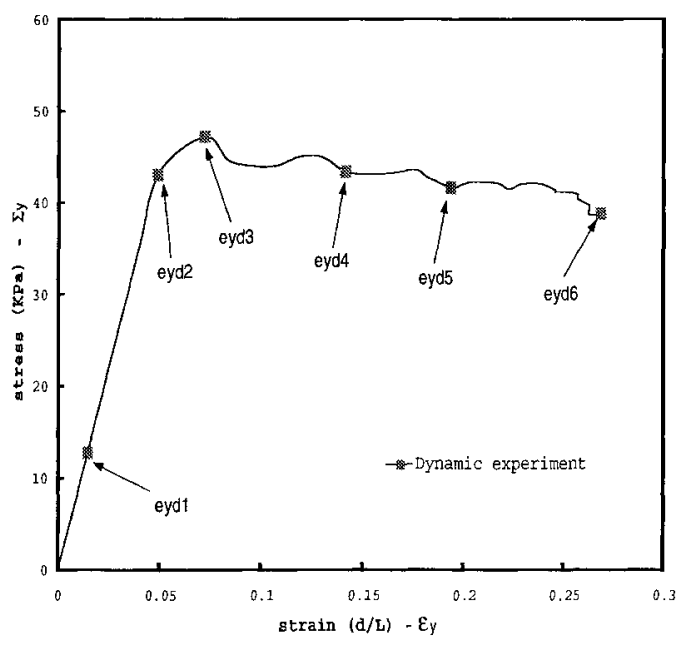

Figure 11: (a) Stress-strain response under dynamic compressive loading in the Y-direction. 


\section{AIAA-2001-1187}
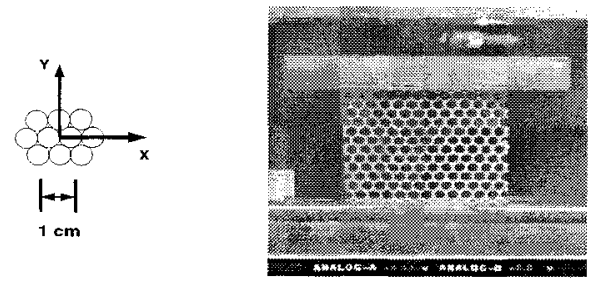

eyd1

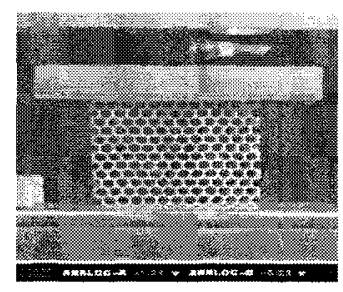

eyd2

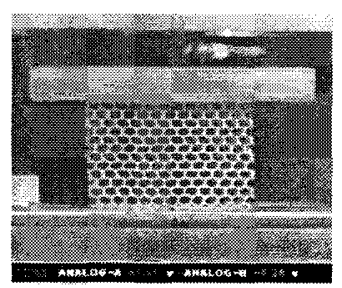

eyd3
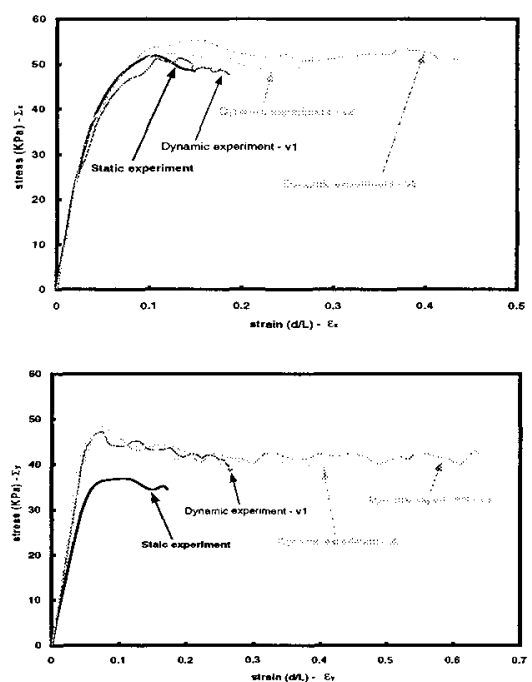

Figure 12: A comparison of static and dynamic experimental responses of the honeycomb material.

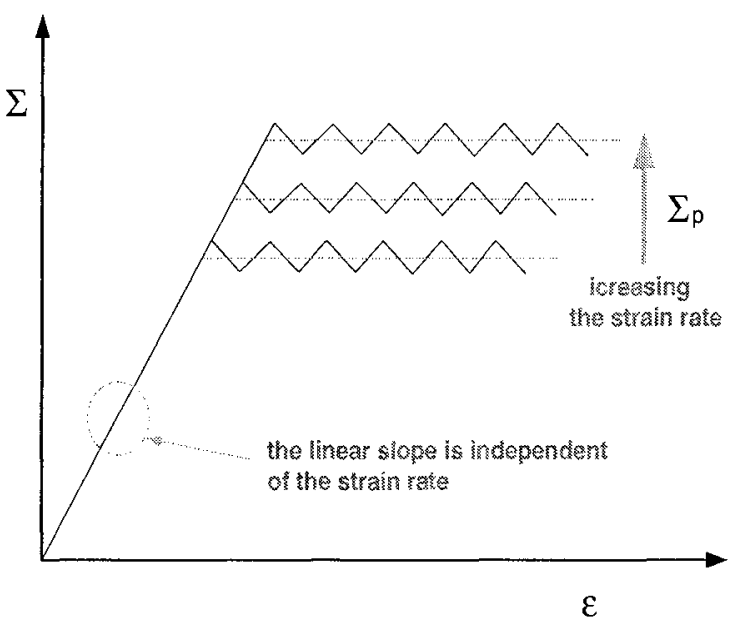

Figure 13: Typical response of honeycomb specimen under static and dynamic loading.

Figure 11: (b)-continued; Experiment - Sequence of deformed honeycomb specimens under dynamic compressive loading in the $\mathrm{Y}$-direction.

Figure 11: (b) Experiment - Sequence of deformed honeycomb specimens under dynamic compressive loading in the $\mathrm{Y}$-direction.

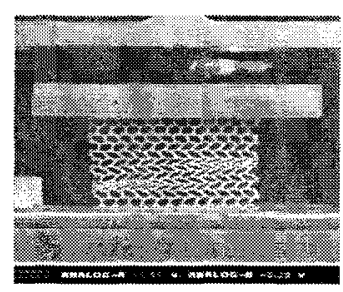

eyd5

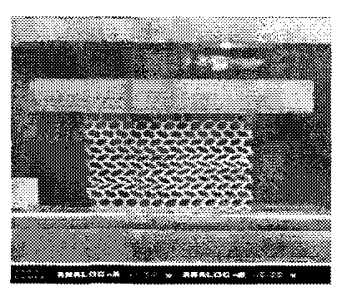

eyd4

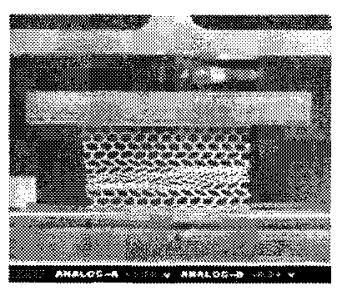

eyd6 